\title{
The Influence of Husband Support and Psychosocial Conditions of Adolescent Pregnancy on Antepartum Depression
}

\author{
$1^{\text {st }}$ A Fatmawati \\ Maternity Nursing Department, Sekolah \\ Tinggi Ilmu Kesehatan 'Aisyiyah \\ Bandung \\ Jl.K.H. Ahmad Dahlan Dalam No. 6, \\ Bandung, Indonesia \\ rianiners@gmail.com
}

\author{
$2^{\text {nd }} \mathrm{N}$ Gartika \\ Medical Surgical Nursing Department \\ Sekolah Tinggi Ilmu Kesehatan \\ 'Aisyiyah Bandung \\ Jl.K.H. Ahmad Dahlan Dalam No. 6, \\ Bandung, Indonesia
}

\author{
$3^{\text {rd }}$ A Alifah \\ Student, Undergraduate Study \\ ProgramSekolah Tinggi Ilmu \\ Kesehatan 'Aisyiyah Bandung \\ Jl.K.H. Ahmad Dahlan Dalam No. 6, \\ Bandung, Indonesia
}

\begin{abstract}
Pregnancy in adolescent mothers could trigger mental disorders. One mental disorder that could be occurred in pregnant women is antepartum depression. This is caused by changes both physically and psychologically. The purpose of this study was to analyze further the relationship between husband support, psychosocial, and physical conditions of adolescent pregnant women with the incidence of antepartum depression. This research was quantitative with a study of a cross-sectional design, which used a consecutive sampling method, 86 adolescent pregnant mothers. They were eligible to participate if their age is in the range of 12 to 19 years; we are in their third trimester of pregnancy. The research instrument used a husband's support questionnaire, psychosocial conditions, and the Edinburgh postnatal depression scale (EPDS). Chi-Square applied to analysis in this study. The results showed that a husband's support was most associated with the incidence of antepartum depression $(p=0.000 ; \alpha=0.05)$ and psychosocial conditions related to the impact of antepartum depression $(p=0.006 ; \alpha=0.05)$. The incidence of antepartum depression in women who get less support was $87.5 \%$, and mothers who have psychosocial conditions at risk of developing antepartum depression by 45.3\%.
\end{abstract}

Keywords-Husband Support, Psychosocial, Adolescent, Depression

\section{INTRODUCTION}

Depression is a mental health disorder characterized by feelings of guilt, depressed moods, low self-esteem, insomnia, loss of interest, and difficulty concentrating [1]. The incidence of depression is 300 million people of all ages [1]. The prevalence of depression during pregnancy is between $11-18 \%$ [2], especially during the second and third trimesters [3]. Depression is a common problem during pregnancy and childbearing [4] and is one of the medical conditions during pregnancy [5].

The leading cause of depression during pregnancy is due to hormonal changes [6], the prevalence is increasing in low-income countries [7] in the range of 5-30\% [8], and $6-31.3 \%$ [9]. Risk factors for depression during pregnancy are poor obstetric history, previous history of mental disorders, lack of social support, financial difficulties, history of violence and unpleasant relationships [7], lack of care about HIV, low socioeconomic and adolescent age [10].

Adolescent pregnancy can be caused by socioeconomic, cultural, lack of information about reproductive health, and the poor to access health services [11]. Births occur in women aged $15-19$ years by $11 \%$ [12]. Around $41 \%$ of these pregnancies are unintended, $26 \%$ are mistimed, and $15 \%$ are unwanted [13]. Unplanned pregnancy will make adolescents vulnerable to STIs and HIV, will have an illegal abortion so that the risk of experiencing birth complications [13]. Adolescent pregnancy will lead to complications of pregnancy and childbirth such as mothers experiencing anaemia, cervical cancer, prolonged labour, thereby increasing the risk of infant death, premature birth and low birth weight, and the risk of eclampsia [14].

Besides physical complications, psychosocial complications will also occur so that the mother will experience poor mental health [3] such as prolonged trauma, experiencing a crisis of confidence, feeling embarrassed and inferior especially if the pregnancy is not planned such as pregnancy due to rape or due to premarital sex [14].

The above conditions can increase the risk of depression in adolescent pregnancy. Risk factors from antepartum depression on adolescent pregnancy are a history of previous adolescent pregnancies, the age of young couples, unwanted pregnancies [15], lack of social support [16]. Mood disorders that consume alcohol and drugs together can cause pregnancy and birth disorders [17].

\section{METHOD}

The research used is quantitative research with crosssectional design. The purpose of this study was to determine the relationship of husband support and psychosocial conditions with the incidence of postpartum 
depression in adolescent pregnant women. The number of samples in this study amounted to 86 teenage pregnant women. The sampling technique was consecutive sampling. Criteria for inclusion of adolescent pregnant women aged 12-19 years, third trimester of pregnancy, marriage, and living with a husband, pregnant women do not have complications. The study was conducted in the fostered areas of Nagrak Health Center, Cimaung Health Center, and Cikalong Health Center in Bandung Regency. The study was conducted in July-August 2019. This study was approved for passing the ethical test from the Ethics Research Committee of STIKes Aisyiyah Bandung with Number: 06 / KEP.02 / STIKes-AB / V / 2019.

Data collection tool in this study using the Edinburgh Postpartum Depression Scale (EPDS), a pregnancy planning questionnaire using The London Measure of Unplanned Pregnancy (LMUP), the husband support questionnaire, and the psychosocial condition questionnaire. Data analysis uses univariate and bivariate analysis. The univariate analysis aims to describe the characteristics of respondents consisting of maternal age, husband's age, husband's education, husband's occupation, husband's income, and home living. Bivariate analysis using chi-square aims to determine the relationship of husband support and psychosocial conditions with the incidence of antepartum depression.

\section{RESULT}

The result of univariate analysis the characteristic of the respondents that the mean age of teenage mothers is 17.98 (18) years, the mean age of the husband is 21.83 (22) years and the mean monthly income of the husband is Rp. $1,648,000$, the husband's education is a high school $(39.5 \%)$; most of the husband's work is as a labourer $(65.1 \%)$, and the most home living is his own / rented house $(45.3 \%)$.

The results of the univariate analysis to illustrate the pregnancy planning, husband support, psychosocial conditions, and antepartum depression can be seen in tables I, II and III.

A. Pregnancy Planning, Husband Support, Psychosocial Condition and Antepartum Depression

TABLE I. FREQUENCY DISTRIBUTION CHARACTERISTICS BASED ON PREGNANCY PLANNING, HUSBAND SUPPORT, PSYCHOSOCIAL CONDITION AND ANTEPARTUM DEPRESSION (N=86)

\begin{tabular}{|l|c|c|}
\hline \multicolumn{1}{|c|}{ Variable } & Frecuency (f) & Percentage (\%) \\
\hline Pregnancy Planning & & \\
\hline Planned & 35 & 40.7 \\
\hline Unplanned & 51 & 59.3 \\
\hline Husband Support & & \\
\hline Good & 38 & 44.2 \\
\hline Lack & 48 & 55.8 \\
\hline Psychosocial Condition & & \\
\hline Risk & 54 & 62.8 \\
\hline No risk & 32 & 37.2 \\
\hline Antepartum Depression & & \\
\hline Depression & 44 & 51.2 \\
\hline No Depression & 42 & 48.8 \\
\hline
\end{tabular}

The table above shows that most pregnancies are unplanned $(59.3 \%)$, most husband support is lacked $(55.8 \%)$, most psychosocial conditions are at risk $(62.8 \%)$, and the majority experience antepartum depression $(51.2 \%)$.

TABLE 2. THE RELATIONSHIP HUSBAND SUPPORT, PSYCHOSOCIAL CONDITION WITH ANTEPARTUM DEPRESSION INCIDENCE IN ADOLESCENT PREGNANT MOTHER $(\mathrm{N}=86)$

\begin{tabular}{|l|c|c|c|c|c|c|}
\hline \multirow{2}{*}{ Independent Variable } & \multicolumn{7}{|c|}{ Antepartum Deprsion Variable } & \multirow{2}{*}{ OR (95\%CI) } & \multirow{2}{*}{ P value } \\
\cline { 2 - 5 } & \multicolumn{2}{|c|}{ No Depression } & \multicolumn{2}{c|}{ Depression } & & \\
\cline { 2 - 5 } & $\mathrm{n}$ & $\%$ & $\mathrm{n}$ & $\%$ & & \\
\hline Husband Support & & & & & 73.5 & 0.000 \\
\hline Good & 42 & 91.3 & 4 & 8.7 & $(18.322-294.855)$ & \\
\hline Lack & 5 & 12.5 & 35 & 87.5 & & \multirow{2}{*}{0.006} \\
\hline $\begin{array}{l}\text { Psychosocial } \\
\text { Condition }\end{array}$ & & & & & & \\
\hline Risk & 17 & 81 & 4 & 19 & $(1.503-16.354)$ & \\
\hline No risk & 30 & 46.2 & 35 & 45.3 & & \\
\hline
\end{tabular}

The results of the analysis above show that adolescent mothers with support from husbands who lack antepartum depression by $87.5 \%$ compared with those who get good support by $8.7 \%$. Chi-square analysis results showed a relationship between a husband's support and the incidence of antepartum depression ( $\mathrm{p}$-value $=0,000$ ). Psychosocial conditions with antepartum depression show that mothers with psychosocial conditions are at risk of experiencing
The results of the bivariate analysis of the relationship between husband support, psychosocial conditions, and antepartum depression are shown in table. antepartum depression by $19 \%$ compared to adolescent pregnant women who are not at risk by $45.3 \%$. The results of the chi-square analysis showed that psychosocial conditions had a relationship with the incidence of antepartum depression ( $\mathrm{p}$-value $=0.006$ ). 


\section{DISCUSSION}

The results showed that adolescent pregnant women experience antepartum depression as much as $51.2 \%$. The age of pregnant women in this study ranged from 15-19 years. Age is one of the risk factors for antepartum depression [10]. Adolescent mothers are at risk of depression during the maternal period, because adolescents have additional new roles and tasks, especially tasks in affective abilities [18]. Some of the results of previous studies of adolescent mothers experience postpartum depression because of the handling of problems during the antepartum [19].

Antepartum depression in adolescent pregnant women is associated with husband support. The results showed that adolescent pregnant women who lacked support from their husbands experienced antepartum depression as much as $87.5 \%$. Risk factors for antepartum depression are caused by a lack of social support and family/partner [7]. Husband's support is one form of social support needed by teenage pregnant women to deal with stress due to physical and psychological changes [20]. Family support, including spouses and social, is a protection mechanism to reduce the incidence of depression and mental health disorders [16]. Social support can come from husbands, parents, friends, and health workers [21]. A good husband and wife relationship will be a good source of social support for maternal psychological well-being [22], [23]. Lack of family and husband support in adolescent mothers can cause anxiety and depression during pregnancy [24], [25].

Antepartum depression in adolescent pregnant women is associated with husband support. The results showed that teenage pregnant women who lacked support from their husbands experienced antepartum depression as much as $87.5 \%$. Risk factors for antepartum depression are caused by a lack of social support and family/partner [7]. Husband's support is one form of social support needed by teenage pregnant women to deal with stress due to physical and psychological changes [17], [20]. Family support, including spouses and social, is a protection mechanism to reduce the incidence of depression and mental health disorders [16].

Social support could come from husbands, parents, friends, and health workers [21]. A good husband and wife relationship will be a good source of social support for maternal psychological well-being [22], [23]. Lack of family and husband support in adolescent mothers can cause anxiety and depression during pregnancy [24]-[27].

Unplanned pregnancy has a relationship between the incidence of antepartum depression [28]. The results showed that $59.3 \%$ of teenage pregnant women did not plan their pregnancies. The incidence of antepartum depression resulting from unwanted pregnancy increased by $21 \%$ [29]. Other studies have shown that unplanned pregnancies, chronic diseases and problems during pregnancy will increase the severity of antepartum depression [30].

Antepartum depression is more common in mothers who do not work and homemakers and husbands who do not work [31]. Low income or financial difficulties are a risk factor for antepartum depression [23], [32].

\section{CONCLUSIONS}

The results of this study indicate that there is a relationship between the support of adolescent pregnant husbands with the incidence of antepartum depression (pvalue 0,000 ), and there is a relationship between the psychosocial condition of adolescent pregnant women with the incidence of antepartum depression (p-value 0.006). The incidence of antepartum depression in women who get less support is $87.5 \%$ and mothers who have psychosocial conditions at risk of developing antepartum depression by $45.3 \%$.

\section{REFERENCES}

[1] WHO. Depression and other common mental disorders: global health estimates, 2017

[2] J. Fisher et al. Prevalence and determinants of common perinatal mental disorders in women in low-and lower-middle-income countries: A systematic review. Bull World Health Organ, 2012, 90(2): 139-149, 2012, doi: 10.2471/BLT.11.091850.

[3] L. Dandona et al. Global, regional, and national life expectancy, all-cause mortality, and cause-specific mortality for 249 causes of death, 1980-2015: a systematic analysis for the Global Burden of Disease Study 2015. Lancet, 2016, 388:1459-1544, doi: 10.1016/S0140-6736(16)31012-1.

[4] A. Staneva, F. Bogossian, M. Pritchard, and A. Wittkowski. The effects of maternal depression, anxiety, and perceived stress during pregnancy on preterm birth: A systematic review. Women and Birth, 2015, 28(3):179-193, doi: 10.1016/j.wombi.2015.02.003.

[5] A. C. Eke, G. Saccone, and V. Berghella. Selective serotonin reuptake inhibitor (SSRI) use during pregnancy and risk of preterm birth: a systematic review and meta-analysis. BJOG An Int. J. Obstet. Gynaecol, 2016, 123(12):1900-1907, doi: 10.1111/1471-0528.14144.

[6] E. M. Sunday, P. C. Okoli, and V. O. Dinwoke. Level of awareness and treatment of anxiety and depression during pregnancy in southeast Nigeria. South African J. Psychiatry, 2018, 24:1-5, doi: 10.4102/sajpsychiatry.v24i0.1192.

[7] A. F. Dadi, E. R. Miller, and L. Mwanri. Antenatal depression and its association with adverse birth outcomes in low and middleincome countries: A systematic review and metaanalysis," PLoS One, 2020, 15(1):1-23, doi: 10.1371/journal.pone.0227323.

[8] N. Mitchell-Jones, I. Gallos, J. Farren, A. Tobias, C. Bottomley, and T. Bourne. Psychological morbidity associated with hyperemesis gravidarum: a systematic review and metaanalysis," BJOG An Int. J. Obstet. Gynaecol., 2017, 124(1) 20 30, doi: 10.1111/1471-0528.14180.

[9] C. A. Woody, A. J. Ferrari, D. J. Siskind, H. A. Whiteford, and M. G. Harris. A systematic review and meta-regression of the prevalence and incidence of perinatal depression. J. Affect Disord., 2017, 219:86-92, doi: 10.1016/j.jad.2017.05.003.

[10] M. Hartley et al. Depressed mood in pregnancy: prevalence and correlates in two Cape Town peri-urban settlements. Reprod. Health, 2011, 8(1):9, doi: 10.1186/1742-4755-8-9.

[11] T. Vos et al. Global, regional, and national incidence, prevalence, and years lived with disability for 310 diseases and injuries, 1990-2015: a systematic analysis for the Global Burden of Disease Study 2015. Lancet, 2016, 388 (10053): 1545-1602, doi: 10.1016/S0140-6736(16)31678-6.

[12] WHO. Adolescent Pregnancy. 2014

[13] D. Beguy, J. Mumah, and L. Gottschalk. Unintended pregnancies among young women living in urban slums: Evidence from a prospective study in Nairobi City, Kenya. PLoS One, 2014, 9(7): 1-10, doi: 10.1371/journal.pone.0101034.

[14] B. Jeannette. Early Marriage Aa a Barrier to Girl's Education: A Developmental Challenge in Africa By Jeannette Bayisenge Assistant lecturer in Department of Social Sciences National University Of Rwanda. Journal of Social Psychology, 2012, 12(6), 23- 48 .

[15] M. Juma, J. Alaii, L. K. Bartholomew, I. Askew, and B. Van Den Born. Understanding orphan and non-orphan adolescents' sexual risks in the context of poverty: A qualitative study in Nyanza 
Province, Kenya. BMC Int. Health Hum. Rights, 2013, 13(1), doi: 10.1186/1472-698X-13-32.

[16] T. Van Heyningen, L. Myer, M. Onah, M. Tomlinson, S. Field, and S. Honikman. Antenatal depression and adversity in urban South Africa. J Affect Disord, 2016, (203):121-129, doi: 10.1016/j.jad.2016.05.052.

[17] O. Balogun, A. Koyanagi, A. Stickley, S. Gilmour, and K. Shibuya. Alcohol consumption and psychological distress in adolescents: A multi-country study. J Adolesc Heal, 2014, 54(2): 228-234, doi: 10.1016/j.jadohealth.2013.07.034.

[18] S. M. Sylvén, T. P. Thomopoulos, N. Kollia, M. Jonsson, and A. Skalkidou. Correlates of postpartum depression in first time mothers without previous psychiatric contact. Eur Psychiatry, 2017, 40: 4-12, doi: 10.1016/j.eurpsy.2016.07.003.

[19] A. Fatmawati and N. Gartika. Hubungan Dukungan Psikososial dan Perencanaan Kehamilan dengan Kejadian Postpartum Blues pada Ibu Remaja. J. BIMTAS, 2019, 3 (2): 44-51.

[20] B. Gelaye, M. Rondon, R. Araya, and M. A. Williams. Epidemiology of maternal depression, risk factors, and child outcomes in low-income and middle-income countries. Lancet Psychiatry, 2016, 3(10): 973-982, doi: 10.1016/S22150366(16)30284-X.

[21] Nurfatimah and C. Entoh. Hubungan faktor demografi dan dukungan sosial dengan depresi pasca salin. J Profesi Med, 2018, 11(2): 89-99, doi: 10.1017/CBO9781107415324.004.

[22] M. A. Easterbrooks, C. Kotake, M. Raskin, and E. Bumgarner. Patterns of Depression Among Adolescent Mothers: Resilience Related to Father Support and Home Visiting Program. Am J Orthopsychiatry, 2016, 86(1): 61-68, doi: 10.1037/ort0000093.

[23] Y. Zeng, Y. Cui, and J. Li. Prevalence and predictors of antenatal depressive symptoms among Chinese women in their third trimester: A cross-sectional survey. BMC Psychiatry, 2015, 15(1): 1-7, doi: 10.1186/s12888-015-0452-7.

[24] F. Agostini, E. Neri, P. Salvatori, S. Dellabartola, L. Bozicevic, and F. Monti. Antenatal Depressive Symptoms Associated with Specific Life Events and Sources of Social Support Among Italian Women. Matern Child Health J, 2015, 19(15): 11311141, doi: 10.1007/s10995-014-1613-x.

[25] A. Fatmawati, I. Nur Rachmawati, and T. Budiati. The influence of adolescent postpartum women's psychosocial condition on mother-infant bonding. Enferm Clin, 2018, 28: 203-206, doi: $10.1016 / \mathrm{S} 1130-8621(18) 30068-8$.

[26] H. Bayrampour, S. McDonald, and S. Tough. Risk factors of transient and persistent anxiety during pregnancy. Midwifery, 2015, 31(6): 582-589, doi: 10.1016/j.midw.2015.02.009.

[27] L. Giardinelli et al. Depression and anxiety in perinatal period: Prevalence and risk factors in an Italian sample. Arch Womens Ment Health, 2012, 15(1): 21-30, doi: 10.1007/s00737-0110249-8.

[28] C. A. Lancaster, K. J. Gold, H. A. Flynn, H. Yoo, S. M. Marcus, and M. M. Davis. Risk factors for depressive symptoms during pregnancy: a systematic review. Am J Obs. Gynecol, 2010, 202(1): 5-14, doi: 10.1016/j.ajog.2009.09.007.Risk.

[29] L. M. Howard, S. Oram, H. Galley, K. Trevillion, and G. Feder. Domestic Violence and Perinatal Mental Disorders: A Systematic Review and Meta-Analysis. PLoS Med, 2013, 10(5), doi: 10.1371/journal.pmed.1001452.

[30] N. Highet, A. L. Stevenson, C. Purtell, and S. Coo. Qualitative insights into women's personal experiences of perinatal depression and anxiety. Women and Birth, 2014, 27(3): 179-184, doi: 10.1016/j.wombi.2014.05.003.

[31] E. Yanikkerem, S. Ay, and N. Piro. Planned and unplanned pregnancy: Effects on health practice and depression during pregnancy. J Obstet Gynaecol Res, 2013, 39(1): 180-187, doi: 10.1111/j.1447-0756.2012.01958.x.

[32] B. Weobong et al. Prevalence and determinants of antenatal depression among pregnant women in a predominantly rural population in Ghana: The DON population-based study. J Affect Disord, 2014, 165: 1-7, doi: 10.1016/j.jad.2014.04.009. 